\title{
Pilot Safety and Feasibility Study of Non-invasive Limb Proprioceptive Cerebellar Stimulation for Epilepsy
}

\author{
Ronald M. Harper ${ }^{1 *}$, Dieter Hertling ${ }^{2,3}$, Ashley Curtis ${ }^{2}$, Eberhardt K. Sauerland ${ }^{4}$ and \\ Christopher M. De Giorgio ${ }^{2,3}$
}

${ }^{1}$ Department of Neurobiology, David Geffen School of Medicine, Univeersity of California, Los Angeles, Los Angeles, CA, United States, ${ }^{2}$ Department of Neurology, Olive View Medical Center, University of California, Los Angeles, Los Angeles, CA, United States, ${ }^{3}$ Department of Neurology, David Geffen School of Medicine, University of California, Los Angeles, Los Angeles, CA, United States, ${ }^{4}$ Department of Physiology, University of Nevada, Reno, NV, United States

OPEN ACCESS

Edited by:

Jeremy Micah Crook University of Wollongong, Australia

Reviewed by:

Qi Gu,

Chinese Academy of Sciences (CAS), China

Adam Lawrence Numis, University of California, San Francisco,

United States

*Correspondence: Ronald M. Harper rharper@ucla.edu

Specialty section:

This article was submitted to Experimental Therapeutics, a section of the journal Frontiers in Neurology

Received: 04 March 2021

Accepted: 19 July 2021

Published: 17 August 2021

Citation:

Harper RM, Hertling D, Curtis A, Sauerland EK and De Giorgio CM (2021) Pilot Safety and Feasibility

Study of Non-invasive Limb Proprioceptive Cerebellar Stimulation for Epilepsy. Front. Neurol. 12:675947.

doi: 10.3389/fneur.2021.675947
Cerebellar stimulation reduces seizures in animals and in humans with drug-resistant epilepsy. In a pilot safety and feasibility study, we applied continuous cutaneous vibratory stimulation (limb proprioceptive cerebellar stimulation) to foot limb proprioceptive receptors to activate cerebellar, pontine, and thalamic structures in drug-resistant epilepsy patients for 8-h nocturnally up to 6-months after a 4-week pre-treatment control baseline. Seizure frequency was evaluated during the baseline control period, and at 6 , 12 , and 24 weeks after the control recordings. Five-subjects completed at least the first 6 -week treatment. At 12-weeks, the median reduction in seizure frequency was $-27.8 \%$ (mean reduction $=-22.3 \%$ ). Two subjects continued for 24 weeks, with a decline of -44.1 and $-45.4 \%$. This pilot study provides support for further clinical studies into the safety and efficacy of limb proprioceptive cerebellar stimulation for epilepsy.

Keywords: neuromodulation, SUDEP, proprioception, seizures, vibration, epilepsy, neurostimulation, cerebellum

\section{INTRODUCTION}

There is evidence that peripheral sensory stimuli suppress epileptic discharges and seizures in animals and humans (1-6). Such peripheral stimulation activates proprioceptive and sensory pathways which project to cerebellar and thalamic structures. Direct electrical, optogenetic, and transcranial magnetic stimulation of the cerebellum has been explored as a means to reduce seizures since the pioneering studies of Cooper and others in the 1970's (7-13). More generalized non-invasive procedures, including hypothermia, transcranial and direct current stimulation of other brain areas, and electrical stimulation of cutaneous surfaces served by trigeminal and vagal nerves have been introduced as well (14-19). Cerebellar regulatory processes are central to protection and recovery from prolonged apnea and extreme hypotension $(20,21)$, conditions central to Sudden Unexpected Death in Epilepsy (SUDEP) $(22,23)$. The frequency of generalized tonic-clonic seizures is also a principal risk factor in SUDEP susceptibility (24). Devices which protect against peri-ictal apnea, hypotension and seizures may theoretically reduce SUDEP risk and reduce seizures in people with drug resistant epilepsy.

New means to reduce the number of seizures and protect against peri-ictal apnea are needed to reduce SUDEP risk in those with drug-resistant epilepsy. Recruitment of cerebellar structures to suppress ictal events may provide such a reduction though peripheral stimulation of proprioceptive receptors via vibration applied externally to peripheral limbs. Such an intervention offers a well-tolerated means to also reduce the severity of apnea, hypopnea and bradycardia accompanying ictal events in a fashion similar to that demonstrated in apnea of prematurity, using limb 
proprioceptive stimulation (25). Animal models also show that stimulation of the sole of the foot reduces seizures in a kainic acid model of epilepsy (26). Given the evidence for protection against apnea in humans, and the antiepileptic effect in animal models, we initiated a trial of non-invasive limb proprioceptive cerebellar stimulation in subjects with drug resistant epilepsy.

\section{MATERIALS AND METHODS}

Participants were recruited from the neurology clinic at Olive View-UCLA Medical Center, a public teaching hospital in the Greater Los Angeles area. Inclusion criteria included ages 18-55 and at least three seizures per month. After institutional review board approval and written informed consent by the patient or guardian, five subjects, aged 22-36 years-old ( 4 males, 1 female) with drug resistant epilepsy were enrolled in this pilot safety and feasibility study of non-invasive limb proprioceptive cerebellar stimulation. Table 1 shows demographic and clinical data for the study group. No changes in antiepileptic drugs were allowed unless needed for seizure safety. All subjects had failed at least three antiseizure medications.

After a 4-week pretreatment baseline, continuous limb proprioceptive cerebellar stimulation was initiated. Stimulation consisted of cutaneous $128 \mathrm{~Hz}$ vibration through $12 \mathrm{~mm}$ disc motors delivered to the sole of the foot for 8-h nightly (Figure 1 and Supplementary Material). Patients or their caregivers tracked seizures using a seizure calendar. Scores from Patient-Reported Outcomes Measurement Information System (PROMIS) indicating sleep integrity and daytime sleepiness were administered at the end of the 24-week period (27).

At enrollment, subjects underwent a SUDEP-7 inventory to identify risk factors for SUDEP $(28,29)$. The SUDEP-7 score is a weighted score of seven risk factors associated with SUDEP, based on findings associated with risk for SUDEP identified in a prospective cohort study (30). Seizure frequency was initially counted as seizures per day, then converted to seizures per month, defined as 30 days per month.

\section{RESULTS}

Table 1 summarizes data for the five subjects. Identifiers that could lead to subject identification, such as actual assigned subject number are not included to ensure confidentiality. All subjects were at high risk for SUDEP, with a mean SUDEP-7 score of 6.8/9 (range 5.0-10.0, normal $=0$ ) $(28,29)$. During the control 4 -week baseline period, the mean seizure frequency was 167.1 seizures per month (range $=3.7-620.1 /$ month).

Following 6-weeks post-baseline nocturnal vibration, median change in seizure frequency was $-27.8 \%$ (mean $=23.8 \%$, range $=$ +3.7 to $-42.7 \%)$. After 12 -weeks, the cumulative median change in seizure frequency was $-27.8 \%$, (mean $=-22.3 \%$, range $=$ -17.1 to $-42.7 \%)$. Two subjects continued using the device for 6-months. After 6-months of limb proprioceptive stimulation, the percent change in seizure frequency for these two subjects was -44.1 and $-45.4 \%$ (Figure 2). Both subjects had severe epileptic encephalopathy with intellectual disability and frequent generalized tonic clonic seizures.

The device was well-tolerated. No skin irritation was reported. No serious device-related or adverse events were reported. PROMIS scores at 6-months following onset of intervention trials showed a reduction in daytime sleepiness.

\section{DISCUSSION}

In this pilot safety and feasibility study, non-invasive limb proprioceptive cerebellar stimulation was safe and well-tolerated. Stimulation was associated with a $-27.8 \%$ median reduction

TABLE 1 | Summary of Subject Data.

\begin{tabular}{|c|c|c|c|c|c|}
\hline \multirow[t]{2}{*}{ Subject } & \multirow{2}{*}{$\begin{array}{c}\text { Baseline } \\
\text { seizure frequency } \\
\begin{array}{c}\text { Seizures per month } \\
\text { (month = } 30 \text { days) }\end{array}\end{array}$} & \multirow{2}{*}{$\begin{array}{l}\text { Duration of epilepsy } \\
\text { Age of onset }\end{array}$} & \multirow[t]{2}{*}{ Seizure types } & \multirow[t]{2}{*}{ Etiology } & \multirow{2}{*}{$\begin{array}{c}\text { SUDEP-7R score } \\
\text { Range 0-10 }\end{array}$} \\
\hline & & & & & \\
\hline \multirow[t]{2}{*}{ A } & 63.3 & 23 years & Multiple seizure types & Tuberous sclerosis Lennox-Gastaut & 7 \\
\hline & & Onset at birth & $\begin{array}{l}\text { Bilateral tonic clonic Focal, impaired } \\
\text { awareness }\end{array}$ & & \\
\hline B & 620.1 & $\begin{array}{l}21 \text { years } \\
\text { Onset at age } 6 \text { months }\end{array}$ & $\begin{array}{l}\text { Multiple seizure types Bilateral tonic } \\
\text { clonic, }\end{array}$ & $\begin{array}{l}\text { Severe epileptic encephalopathy } \\
\text { Lennox-Gastaut 6p25.1 mutation }\end{array}$ & 7 \\
\hline \multirow[t]{2}{*}{ C } & 49.7 & 21 years & Multiple seizure types & Lennox-Gastaut & 7 \\
\hline & & Onset at age 7 months & $\begin{array}{l}\text { Bilateral tonic clonic, Focal, impaired } \\
\text { awareness }\end{array}$ & & \\
\hline $\mathrm{D}$ & 3.7 & $\begin{array}{l}5 \text { years } \\
\text { Onset at age } 26 \text { years }\end{array}$ & Focal, impaired awareness & Unknown etiology & 4 \\
\hline \multirow[t]{2}{*}{ E } & 99.3 & 31 years & Multiple seizure types & Cortical dysplasia & 8 \\
\hline & & Onset at age 5 years & $\begin{array}{l}\text { Bilateral tonic clonic Focal, impaired } \\
\text { awareness }\end{array}$ & & \\
\hline
\end{tabular}

Identifiers removed to protect personal health information and confidentiality. 
A

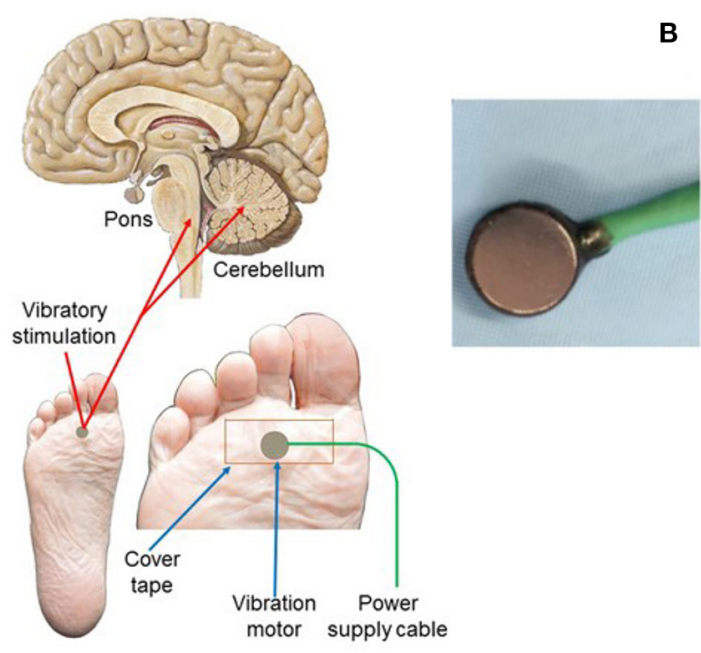

C

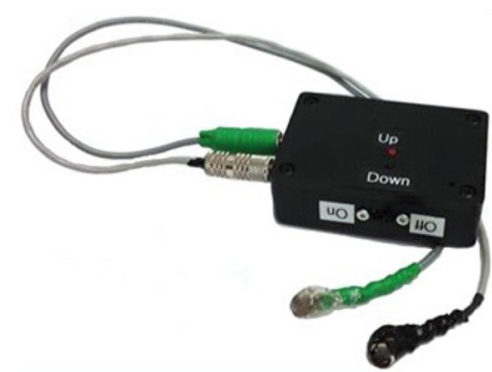

FIGURE 1 | Vibratory placement, brain targets, and stimulation components of limb proprioceptive device. (A) Placement of vibrator motor on the sole of the foot, using non-allergenic tape for adherence; power supply leads provide power to the vibratory motor at 3.0 V. Central targets for vibration include the cerebellum and dorsal pons. (B) Vibrator motor with power leads. (C) Power supply containing two 1.5VAA batteries with two levels of vibratory stimulation (up $=3.0 \mathrm{~V}$; down $=1.5 \mathrm{~V}$; vibration was always at $3.0 \mathrm{~V}$ in this study).

Component sources and vibratory motor specifications are outlined in Supplementary Material.
$(-22.3 \%$ mean reduction) in seizure frequency after 3-months of stimulation. Two subjects continued to 6-months, and both experienced $>40 \%$ reduction in seizure counts. This outcome emerged despite a high rate of seizures in the study group. The outcomes compare favorably with transcutaneous vagal nerve electrical stimulation [for vagal stimulation: $-23.4 \%$ after 28 days; $-34.2 \%$ after 20 weeks; (19)], and offer benefits of mild vibration rather than electrical stimulation.

Electrical stimulation of the cerebellum or excitation of the cerebellar fastigial nucleus reduce seizures significantly (8). A role for the cerebellum in triggering or suppressing seizures has repeatedly been suggested [for review, see (31)]. Proprioceptive stimulation, with ascending neural signaling via posterior column pathways, activates deep cerebellar nuclei, including the fastigial nuclei critical for such influences over seizures. Functional magnetic resonance imaging studies indicate that proprioceptive stimulation triggered by limb movements activates cerebellar deep nuclei and parabrachial pontine structures, as well as thalamic and insular regions, all significant areas for regulating seizure expression (32).

The proprioceptive stimulation may exert ancillary benefits for patients with epilepsy in addition to reducing seizure frequency. Apnea, hypoxemia, and bradycardia play key roles in the terminal mechanisms of $\operatorname{SUDEP}(22,23)$. Interventions to reduce seizures and apnea, and provide cardiovascular support are urgently needed to reduce SUDEP risk. Cerebellar and brainstem structures that mediate recovery from apnea and hypotension $(20,21)$ demonstrate substantial injury and volume loss in people with epilepsy who later succumb to SUDEP (33). Non-invasive proprioceptive stimulation using a device similar to that described here reduces the severity of apneas, hypopneas, and bradycardic episodes in infants with apnea of prematurity and periodic breathing, presumably operating through cerebellar contributions to respiratory motor and autonomic coordination $(25,34)$. Since breathing and cardiovascular issues can add to
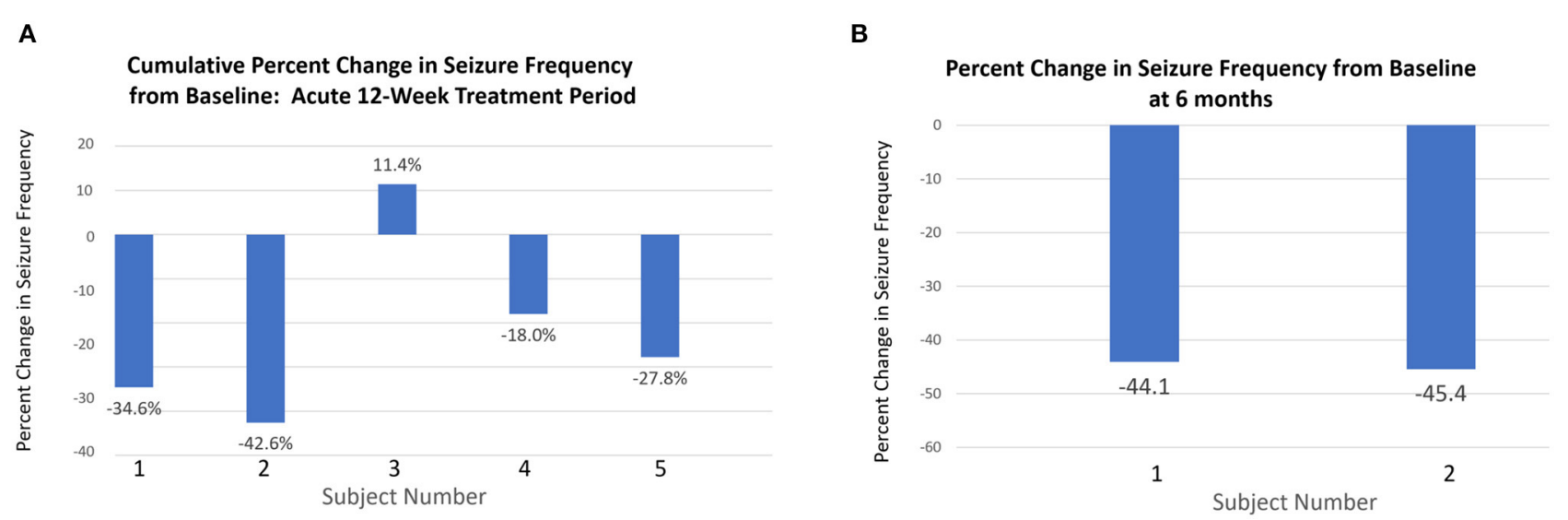

FIGURE 2 | Changes in seizure frequency at 12 weeks and 6 months. (A) Percentage change in total seizure frequency at 12 weeks relative to baseline for all patients. (B) Two subjects (1 and 2) who continued with the intervention for 6 months showed greater percentage reduction in seizure frequency from baseline to 6 months than at 12 weeks. 
neural injury accompanying seizure discharge, benefits in seizure reduction may be supplemented by respiratory and cardiac support.

\section{LIMITATIONS}

The primary purpose of this study was to evaluate safety and tolerability, with a secondary aim of preliminary efficacy. The principal limitation was the small number of subjects, resulting from logistic constraints of prolonged data acquisition in a pilot study. The constraints also did not allow more prolonged, or different patterns of vibratory exposure, e.g., daytime exposure, which may have resulted in greater effectiveness. The small number and open nature of the investigation precludes definitive conclusions on efficacy, or which type of epilepsy would be most responsive to stimulation.

This report provides initial data that non-invasive limb proprioceptive cerebellar stimulation is a safe and novel intervention that may reduce seizure frequency in people with drug resistant epilepsy. The device is minimal risk, with low possibility for discomfort or skin injury, or interference with pacemakers, and is well-tolerated. Non-invasive limb proprioceptive cerebellar stimulation has the potential to reduce seizure frequency in people with epilepsy, and has been shown to reduce the risk of apnea, hypopnea, and associated bradycardia in premature infants (25) and spinal cord-injured patients (35). The vibratory intervention is minimally invasive, does not injure the skin as is possible with sustained electrical stimulation, and is very well-tolerated by sleeping individuals.

\section{CONCLUSIONS}

Non-invasive limb proprioceptive cerebellar stimulation was safe and well-tolerated. Preliminary data from this small cohort with severe epilepsy at risk for SUDEP indicate subjects experienced a median change in cumulative seizure frequency of $-27.8 \%$ (mean $=-22.3 \%)$ at 12 -weeks, with reductions of as much as $45.4 \%$ with more prolonged stimulation. The intervention offers a non-invasive and low-cost means to lower the number of seizures with minimal disruption to sleep. Further investigation

\section{REFERENCES}

1. Forster FM, Penfield W, Jasper H, Madow L. Focal epilepsy, sensory precipitation and evoked potentials. Electroenceph Clin Neurophysiol. (1949) 1:349-56. doi: 10.1016/0013-4694(49)90200-X

2. Jackson JH. From "Selected writings of John Hughlings Jackson." New York, NY: Basic Books (1958). vol 1.

3. Symonds C. Excitation and inhibition in epilepsy. Brain. (1959) 82:133-46. doi: $10.1093 /$ brain/82.2.133

4. Symonds C. Some observations on the facilitation or arrest of epileptic seizures. In: Garland H, editor. Scientific Aspects of Neurology. Edinburgh: Livingstone (1961). p. 142-52.

5. Paulson GW. Inhibition of seizures. Dis Nerv Syst. (1963) 24:657-64.

6. Tassinari CA. Suppression of focal spikes by somato-sensory stimuli. Electroenceph Clin Neurophysiol. (1968) 25:574-8. doi: 10.1016/0013-4694(68)90237-X of limb non-invasive cerebellar stimulation to reduce seizures in drug resistant epilepsy is indicated.

\section{DATA AVAILABILITY STATEMENT}

The raw data supporting the conclusions of this article will be made available by the authors, without undue reservation.

\section{ETHICS STATEMENT}

The studies involving human participants were reviewed and approved by Olive View Medical Center IRB. The patients/participants provided their written informed consent to participate in this study.

\section{AUTHOR CONTRIBUTIONS}

$\mathrm{RH}$ and CD participated in conceptualization, design, analysis, and writing. ES was involved in conceptualization and writing. $\mathrm{DH}$ created electrode patches and assisted in spreadsheet creation, data entry, and analysis. AC was involved in patient recruitment, data entry, and analysis. All authors contributed to the article and approved the submitted version.

\section{FUNDING}

This research was supported by unrestricted funds to UCLA from: The Fidelity Charitable Nancy Adams and Scott Schoen Fund; the Kraig and Linda Kupiec Family Trust; and the James and Beverly Peters and Family.

\section{ACKNOWLEDGMENTS}

We thank Diana Murray for patient recruitment efforts.

\section{SUPPLEMENTARY MATERIAL}

The Supplementary Material for this article can be found online at: https://www.frontiersin.org/articles/10.3389/fneur. 2021.675947/full\#supplementary-material
7. Cooper IS, Amin I, Riklan M, Waltz JM, Poon TP. Chronic cerebellar stimulation in epilepsy: clinical and anatomical studies. Archiv Neurol. (1976) 33:559-70. doi: 10.1001/archneur.1976.00500080037006

8. Davis R. Cerebellar stimulation for seizure control. In: Lozano AM, Gildenberg RR, Tasker RR, editors. Textbook of Stereotactic and Functional Neurosurgery. 1st ed. Heidelberg: Springer-Verlag (2009) p. 2823-37.

9. Streng ML, Krook-Magnuson E. Excitation, but not inhibition, of the fastigial nucleus provides powerful control over temporal lobe seizures. J Physiol. (2020) 598:171-87. doi: 10.1113/JP278747

10. Fountas KN, Kapsalaki E, Hadjigeorgiou G. Cerebellar stimulation in the management of medically intractable epilepsy: a systematic and critical review. Neurosurg Focus. (2010) 29:E8. doi: 10.3171/2010.5.FOCUS 10111

11. Brighina F, Daniele O, Piazza A, Giglia G, Fierro B. Hemispheric cerebellar rTMS to treat drug-resistant epilepsy: case reports. Neurosci Lett. (2006) 397:229-33. doi: 10.1016/j.neulet.2005.12.050 
12. Krook-Magnuson E, Szabo GG, Armstrong C, Oijala M, Soltesz I. Cerebellar directed optogenetic intervention inhibits spontaneous hippocampal seizures in a mouse model of temporal lobe epilepsy. eNeuro. (2014) 1:ENEURO.000514.2014. doi: 10.1523/ENEURO.0005-14.2014

13. Kros L, Eelkman Rooda OHJ, De Zeeuw CI, HoebeekFE. Controlling cerebellar output to treat refractory epilepsy. Trends Neurosci. (2015) 38:78799. doi: 10.1016/j.tins.2015.10.002

14. Nitsche MA, Paulus W. Noninvasive brain stimulation protocols in the treatment of epilepsy. Neurotherapeutics. (2009) 6:244-50. doi: 10.1016/j.nurt.2009.01.003

15. Motamedi GK, Lesser RP, Vicini S. Therapeutic brain hypothermia, its mechanisms of action, and its prospects as a treatment for epilepsy. Epilepsia. (2013) 54:959-70. doi: 10.1111/epi.12144

16. VanHaerents S, Chang BS, Rotenberg A, Pascual-Leone A, Shafi MM. Noninvasive brain stimulation in epilepsy. J Clin Neurophysiol. (2020) 37:11830. doi: 10.1097/WNP.0000000000000573

17. DeGiorgio CM, Soss J, Cook IA, Markovic D, Gornbein J, Murray D, et al. Randomized controlled trial of trigeminal nerve stimulation for drug-resistant epilepsy. Neurology. (2013) 80:786-91. doi: 10.1212/WNL.0b013e318285c11a

18. Ellrich J. Transcutaneous Auricular Vagus Nerve Stimulation. J Clin Neurophysiol. (2019) 36:437-42. doi: 10.1097/WNP.0000000000000576

19. Bauer S, Baier H, Baumgartner C, Bohlmann K, Fauser S, Graf W, et al. Transcutaneous vagus nerve stimulation (tVNS) for treatment of drugresistant epilepsy: a randomized, double-blind clinical trial (cMPsE02). Brain Stimul. (2016) 9:356-63. doi: 10.1016/j.brs.2015.11.003

20. Lutherer LO, Lutherer BC, Dormer KJ, Janssen HF, Barnes CD. Bilateral lesions of the fastigial nucleus prevent the recovery of blood pressure following hypotension induced by hemorrhage or administration of endotoxin. Brain Res. (1983) 269:251-7. doi: 10.1016/0006-8993(83)90134-8

21. Xu F, Frazier DT. Role of the cerebellar deep nuclei in respiratory modulation. Cerebellum. (2002) 1:35-40. doi: 10.1080/1473422027532 03078

22. Ryvlin P, Nashef L, Lhatoo SD, Bateman LM, Bird J, Bleasel A, et al. Incidence and mechanisms of cardiorespiratory arrests in epilepsy monitoring units (MORTEMUS): a retrospective study. Lancet Neurol. (2013) 12:966-77. doi: 10.1016/S1474-4422(13)70214-X

23. Vilella L, Lacuey N, Hampson JP, Rani MRS, Sanju RK, Friedman $\mathrm{D}$, et al. Postconvulsive central apnea as a biomarker for sudden unexpected death in epilepsy (SUDEP). Neurology. (2019) 92:171-82. doi: 10.1212/WNL.0000000000006785

24. DeGiorgio CM, Markovic D, Mazumder R, Moseley BD. Ranking the leading risk factors for sudden unexpected death in epilepsy. Front Neurol. (2017) 8:473. doi: 10.3389/fneur.2017.00473

25. Kesavan K, Frank P, Cordero D, Benharash P, Harper RM. Neuromodulation of limb proprioceptive afferents decreases apnea of prematurity and accompanying intermittent hypoxia and bradycardia. PLoS ONE. (2016) 11:e0157349. doi: 10.1371/journal.pone.0157349

26. Kang X, Shen X, Xia Y. Electroacupuncture-induced attenuation of experimental epilepsy: a comparative evaluation of acupoints and stimulation parameters. Evid Based Complement Alternat Med. (2013) 2013:149612. doi: $10.1155 / 2013 / 149612$
27. Hanish AE, Lin-Dyken DC, Han JC. PROMIS sleep disturbance and sleep-related impairment in adolescents: examining psychometrics using self-report and actigraphy. Nurs Res. (2017) 66:246-51. doi: 10.1097/NNR.0000000000000217

28. DeGiorgio CM, Miller P, Meymandi S, Chin A, Epps J, Gordon S, et al. RMSSD, a measure of vagus-mediated heart rate variability, is associated with risk factors for SUDEP: the SUDEP-7 Inventory. Epilepsy Behav. (2010) 19:78-81. doi: 10.1016/j.yebeh.2010.06.011

29. Novak JL, Miller PR, Markovic D, Meymandi SK, DeGiorgio CM. Risk assessment for sudden death in epilepsy: the SUDEP-7 inventory. Front Neurol. (2015) 9:252. doi: 10.3389/fneur.2015.00252

30. Walczak TS, Leppik IE, D’Amelio M, Rarick J, So E, Ahman P, et al. Incidence and risk factors in sudden unexpected death in epilepsy: a prospective cohort study. Neurology. (2001) 56:519-25. doi: 10.1212/WNL.56.4.519

31. Marcian V, Filip P, Bares M, Brazdil M. Cerebellar dysfunction and ataxia in patients with epilepsy: coincidence, consequence, or cause? Tremor Other Hyperkinet Mov. (2016) 6:376. doi: 10.5334/tohm.331

32. Harper RM, Kumar R, Macey PM, Woo MA. Neural responses to paced breathing in congenital central hypoventilation syndrome. Soc Neurosci. (2005) 352:1.

33. Allen LA, Vos SB, Kumar R, Ogren JA, Harper RK, Winston GP, et al. Cerebellar, limbic, and midbrain volume alterations in sudden unexpected death in epilepsy. Epilepsia. (2019) 60:718-29. doi: 10.1111/epi.14689

34. Potts JT, Rybak IA, Paton JFR. Respiratory rhythm entrainment by somatic afferent stimulation. J Neurosci. (2005) 25:1965-78. doi: 10.1523/JNEUROSCI.3881-04.2005

35. Woo MS, Valladares E, Montes L, Sarino M, Harper RM. Proprioceptor stimulation improves sleep disordered breathing in adolescents and young adults with Asia A paraplegia. Am J Resp Crit Care Med. (2014) 189:A1280.

Conflict of Interest: The University of California has filed for a provisional patent for the device described in the manuscript, listing RH, CD, and ES as inventors.

The remaining authors declare that the research was conducted in the absence of any commercial or financial relationships that could be construed as a potential conflict of interest.

Publisher's Note: All claims expressed in this article are solely those of the authors and do not necessarily represent those of their affiliated organizations, or those of the publisher, the editors and the reviewers. Any product that may be evaluated in this article, or claim that may be made by its manufacturer, is not guaranteed or endorsed by the publisher.

Copyright (c) 2021 Harper, Hertling, Curtis, Sauerland and De Giorgio. This is an open-access article distributed under the terms of the Creative Commons Attribution License (CC BY). The use, distribution or reproduction in other forums is permitted, provided the original author(s) and the copyright owner(s) are credited and that the original publication in this journal is cited, in accordance with accepted academic practice. No use, distribution or reproduction is permitted which does not comply with these terms. 